This is the accepted manuscript of the article, which has been published in Style. 2019, 53(4), 457-463. http://dx.doi.org/10.5325/style.53.4.0457

post-print version of a response article published in Style 53:4, pp. 457-463

DOI: $10.5325 /$ style.53.4.0457

https://www.jstor.org/stable/10.5325/style.53.4.0457

\title{
Disagreeing with Fictionality? A Response to Richard Walsh in the Age of Post- Truth Politics and Careless Speech
}

\section{Maria Mäkelä}

Tampere University

In the 2019 parliamentary elections, the Finnish populist nationalist party True Finns campaigned with a seven-minute YouTube video abounding with what Aarhus-based fictionality scholars Henrik Skov Nielsen and Simona Zetterberg Gjerlevsen would call intentional "signals" of fictionality. Mixing footage with animation, the video manages to come across as a parody of several genres of speculative fiction: Marvel comics, dystopian Hollywood blockbuster films, video games. It tells a story of a blood-thirsty "Pissed Off" monster created by the accumulating frustration and anger of the people witnessing the corruption of the elite and mainstream media who use immigration to further their own vicious ends. The video begins with the party leader Jussi Halla-aho holding a comic in his hands in a dark library and ends with a direct address to the viewer: "As you know, there is no pissed off monster and it's not going to come and save anyone. The old parties are not going to change their objectives. If you want change, you have to vote for change. Use your power.",

The video, representing violence and sabotage both toward government institutions and on the streets, worked as it was supposed: appalled social media users 
took care of the distribution and the video was rapidly all over the media. Several social sciences and humanities scholars were asked to comment on the video, myself included. In my reply to the national broadcasting company I mentioned that the video is a perfect example of what my narratological colleagues nowadays might call the "rhetorical force of fictionality" (as in the target essay by Walsh). In the public debate surrounding the campaign video, fictionality played completely into the hands of True Finns, the rhetorical force of fictionality culminating in the party leader's characteristically sour public response to accusations of inciting political violence: "So now you want to ban movies too?" The controversy can be roughly understood as a struggle over generic macroframing in public discourse: the True Finns PR machinery obviously benefitted from foregrounding the video's aesthetic quality as a pastiche of - not just any fictional genres but precisely—speculative fiction which, in all its speculativeness, might come across as fictional even to a second degree in the public understanding (although not according to rhetorical definitions of fictionality). The opposing framing activities, in turn, reminded of the affective potential of fictional representations, and rightly so. In research, this stance is best exemplified by Noël Carroll, as referenced in Richard Walsh's target essay: “it is possible to entertain a proposition as unasserted, and yet have an emotional response to it" (Walsh 16). Yet, despite of raising public awareness of the affective potential of political fictions, many of the responses by politicians and other influencers at the other end of the political spectrum were exceedingly naivé, discussions focusing, for example, on whether a man actually got killed in the fictional universe of the video. So, alas, even the attempts at criticism by the political opponents were subsumed within the rhetoric of fictionality, and the moral of the narrative act was reduced to the moral of the 
story. Yet another populist strategy proved a complete success, with fictionality directing political action.

Having now read Walsh's target essay, I am increasingly convinced that the new rhetorical theory of fictionality promoted by Wash, the Aarhus scholars, and now also James Phelan, has much more to offer for the study of fictionality in nonliterary contexts than it has for the study of generic fictions, with the possible exception of the diachronic perspective listed in Walsh's concluding prospects for future study. For example, I do not find Walsh's example of Mrs. Dalloway's ending at all helpful in understanding how a rhetorical-fictional approach to much-studied fiction would help us delineate all the possible noninformative "relevance" or "points" of fictional narration. Instead, I find Walsh's approach to fictionality as a rhetorical strategy in any discourse extremely helpful in elaborating on the relationship between contemporary storytelling practices and what has come to be called the post-truth era, or more specifically, post-truth politics. From this perspective, the most concrete, graspable rhetorical affordance of fictionality is its resistance to the much-touted cure for post-truthfulness, namely fact-checking: it can be deduced from Walsh's definition of fictionality that a fictional proposition cannot be falsified. This implication of the rhetorical fictionality theory is surprisingly little discussed. Stefan Iversen and Henrik Skov Nielsen touch upon it briefly in their analysis of Barack Obama's rhetoric of fictionality, noting, for example, that "[m]aking nonfictional claims about fictional statements might even be perceived as pathological" (137). Yet Iversen and Nielsen's blatant admiration for Obama as an orator averts them from addressing this affordance in the wider context of post-truthfulness and genuinely thinking through the possible political implications of such rhetoric. 
In fact, as Walsh's own well-chosen example of the all-too-familiar prototype of the pub prankster demonstrates, a fictional account embedded in nonfictional context resist—not only falsification but—any relevant response from the interlocutor. Thus an intuitive consideration would suggest that fictionality as a rhetorical resource rather suppresses than invites dialogue, at least as far as informativity, in Walsh's terms, is concerned. This was indeed the case with the True Finns campaign video, as well as numerous other publicity stunts by populist parties around Europe: one cannot challenge their claims by providing contrasting information, expert point of view, or data, and what one is left with is an invitation to react affectively - and in the social media-dominated narrative environments, moreover, share affectively. In the story economy of social media, where narrative rhetoric is transformed into a rhetoric of sharing, it is precisely the affective reaction to storytelling and not the narrative's informative content that is being foregrounded in the collective "cognitive economy of communication" (see target essay). Therefore, social media are well suited to amplify the rhetorical power of fictionality understood in the Walshian sense, as a communication whose relevance does not rely upon its referential or other type of informativity.

Fictionality's potential to mute opposing points of view is not only a logical consequence (to argue against—what?), but has its roots in the long history of storytelling. Locating the rhetorical power of fictionality in its "beyond referentiality" status is prominent through the entire history of Western rhetoric. As Walsh notes in his target essay, the idea of "higher," nonreferential and hence universal truth of fiction, dating back to Aristotle's notion of poiesis, is roughly in tandem with Walsh's own definition of fictionality as a rhetorical gesture whose position toward informativity is at the same time reflective, indirect, and indifferent (Walsh 18). 
Moreover, the cultures of storytelling from Aristotle to Enlightenment were more or less dominated by the logic of the exemplum: the point of the story, whether invented or rooted in historical events, was to provide a moral example; the backdrop against which a narrative was to be evaluated was not that of reference but of the underlying, shared structure of norms and values, authorized by God, the sovereign, or other such fixed authority.

Moreover, stories with morals never ceased to exist in the modern times, and the current rise of populism and neo-moralism is partly fueled by the renaissance of narrative didacticism. I have argued elsewhere (Mäkelä, Lessons) that the story logic of social media favors exemplarity over referentiality. It replaces fixed authority with emergent authority, created by the like-minded circulation and reframing of experientially loaded narratives. Such social-media induced changes in rhetoric pertain particularly to narrative form. The social media afterlife of viral narratives is a material manifestation of the alleged universality of narrative truth - the product of engaging social media storytelling is "true in so many ways," regardless of its origin either as an utterance (who told you this?) or as a representation (did it actually happen?). The affective and experiential truth is cemented in the concrete shares and likes, and even if the original narrative were falsified, the shared experience remains intact and "true."

Thus far I have only considered Walsh's theory in contexts that are unquestionably narrative, and indeed, I am in strong agreement with Walsh's (somewhat cautious) suggestion that the rhetorical notion of fictionality should be limited to narrative rhetoric, instead of covering for any indirect, figurative, or imagination-induced rhetorical gesture. Walsh arrives at this distinction a bit hesitantly for the obvious reason that this limitation appears to be more embedded in 
the scholarly tradition and conventional language use than being a logical consequence of relevance theory. Another reason for Walsh to not be fully explicit in delimiting fictionality to narrative rhetoric might be that along with narrative comes worldmaking, which in turn speaks for those ontological worldmaking theories of fictionality that Walsh wants to dissociate himself from. Yet the perennial questions relating to "fictional truth" in rhetoric and literary studies, clearly focusing on narrative forms, are so close to Walsh's concerns that this limitation comes almost naturally. In research, distinctions are often more welcome than generalizations. That being said, the doctrine of relevance, coupled with narrativity, issues another challenge, for narrative rhetoric in its prototypically experiential form (as defined by the first-generation cognitive narratologists), even if conforming to actual experience, is not primarily an informative mode. Hence telling apart nonfictional narrativity from fictional based on the question of informative relevance may turn out to be complicated.

All in all, contemporary narrative environments abound with wonderful test cases for a rhetorical fictionality scholar, yet the muddy waters of manipulative rhetoric online will produce ever new challenges to theorists like Walsh who are keen on producing universal definitions. Sometimes fuzzy sets need fuzzy methods and terminology. One of my recent favorites among approaches to post-truthfulness resonates with the dark side of Walsh's notion of fictionality: political scientist AriElmeri Hyvönen coins the term "careless speech" (as an antimony of Foucault's "fearless speech") to denote political discourse that is unconcerned not only with truth but also with the world as a common space in which things become public. It means an unwillingness to engage with other perspectives, a reluctance to accept that speech has repercussions and words 
matter. It involves creating uncertainty over whether what is said aloud is actually meant; it means believing that anything can be unsaid. [ . . . Rather than trying to persuade, careless speech seeks to create confusion and bring democratic debate to a halt. (3)

The True Finns campaign video as a rhetorical gesture does precisely that: it is excessively marked as fiction, pretending as not having any consequences in the actuality as a speech act. With its superfluous fictionality, it both thwarts any attempt at a reasonable critique as well as anticipates the affective responses that can then be turned against the critics who wind up looking like fools who cannot tell fact from fiction. Yet, as becomes evident from Hyvönen's definition, “careless speech" rarely flaunts its fictionality the way my example video does. In the contemporary political context, rhetorical gestures implying nonchalance toward informativity or factual truths appear to serve rather community-strengthening and thus also excluding than conventionally persuading functions. Therefore, it is not enough to concentrate on the orator, but one needs to take into account the collective meaning-making practices; in the context of fictionality and stories that are "true in so many ways" (but not factually), we might also speak of "careless interpretation" (see also Nurminen).

What is crucially needed are pragmatic and empirical mappings of the affordances of fictionality in narrative environments where the role of fictionality has been hitherto undermined. If not properly methodized, the Walshian approach will remain in the shadow of theories emphasizing fictional worldmaking, for these are the theories that are supported — in intuitive and popular understanding — by the contemporary cultural dominant: speculative fiction. While the True Finns campaign video takes the most out of this macro genre, Walsh's theory explains much more convincingly its cunning rhetorical, contextual, and collective dynamic than any of 
the previous, ontologically oriented approaches. Technical as it may seem, Walsh's theory of fictionality may prove the next big contextualist thing in narrative theory.

[BIO] MARIA MÄKELÄ is Senior Lecturer in Comparative Literature and Director of Narrare: Centre for Interdisciplinary Narrative Studies at Tampere University. In 2018, she was Visiting Professor at the Centre for Fictionality Studies, Aarhus University. In 2019, she is President of the International Society for the Study of Narrative. She is coeditor of Narrative, Interrupted (De Gruyter) and Narrative Theory, Literature, and New Media (Routledge). She has published on consciousness, voice, and realism across media, the literary tradition of adultery, authorial ethos, and critical applications of postclassical narratologies in, for example, Narrative, Poetics Today, Partial Answers, and Style. She heads three projects dealing with the instrumentalization of narratives.

Notes

This response essay was written in the context of the consortium project "Instrumental Narratives: The Limits of Storytelling and New Story-Critical Narrative Theory" (no. 314768), funded by the Academy of Finland.

\section{Works Cited}

Hyvönen, Ari-Elmeri. “Careless Speech: Conceptualizing Post-Truth Politics.” New Perspectives: Interdisciplinary Journal of Central \& East European Politics and International Relations, vol. 26, no. 3, 2018, pp. 1-25.

Iversen, Stefan, and Henrik Skov Nielsen. "Invention as Intervention in the Rhetoric of Barack Obama.” Storyworlds, vol. 9, no. 1-2, 2017, pp. 121-142.

Mäkelä, Maria. "Lessons from the Dangers of Narrative Project: Toward a Story-Critical 
Narratology.” Tekstualia, vol. 2018, no. 4, pp. 175-186.

Nurminen, Matias. 'Narrative Warfare. The 'Careless' Reinterpretation of Literary Canon in Online Antifeminism." Narrative Inquiry, vol. 29, no. 2, 2019, pp. $312-331$.

NOTE

i The video with English subtitles is available at https://www.youtube.com/watch?v=dzCK4tTu2nE 